\title{
Load-bearing capacities of ultra-thin occlusal veneers bonded to dentin
}

\author{
Maeder, Mila ; Pasic, Pavla ; Ender, Adreas ; Özcan, Mutlu ; Benic, Goran I ; Ioannidis, Alexis
}

\begin{abstract}
OBJECTIVES To test whether the load-bearing capacity of occlusal veneers made of ceramic or hybrid materials bonded to dentin does differ from those of porcelain-fused-to metal or lithium disilicate glass ceramic crowns. MATERIAL AND METHODS In 80 human molars, occlusal tooth substance was removed so that the defects extended into dentin, simulating defects caused by attrition/erosion. Restorations at a standardized thickness of either $0.5 \mathrm{~mm}$ or $1.0 \mathrm{~mm}$ were digitally designed. For both thicknesses, 4 test groups $(\mathrm{n}=10$ per group) were defined, each including a different restorative material: "0.5-ZIR": $0.5 \mathrm{~mm}$ thick zirconia (Vita YZ HT); "1.0-ZIR": $1.0 \mathrm{~mm}$ thick zirconia (Vita YZ HT); "0.5-LDC": $0.5 \mathrm{~mm}$ thick lithium disilicate ceramic (IPS e.max Press); "1.0-LDC": $1.0 \mathrm{~mm}$ thick lithium disilicate ceramic (IPS e.max Press); "0.5-HYC": $0.5 \mathrm{~mm}$ thick PICN (Vita Enamic); "1.0-HYC": $1.0 \mathrm{~mm}$ thick PICN (Vita Enamic); "0.5-COC": $0.5 \mathrm{~mm}$ thick tooth shaded resin composite (Lava Ultimate) and "1.0-COC": $1.0 \mathrm{~mm}$ thick tooth shaded resin composite (Lava Ultimate). Consecutively, the specimens were thermo-mechanically aged and then loaded until fracture. The load-bearing capacities (F) between the groups were statistically compared using the Kruskal-Wallis test $(\mathrm{p}<0.05)$ and pairwise group comparison applying the Dunn's method. In addition, the results were compared to those of conventional lithium-disilicate ceramic crowns ("CLD") and to porcelain-fused to metal crowns ("PFM"). RESULTS The median $\mathrm{F}$ values for the $0.5 \mathrm{~mm}$ thin restorations were 1'350 $\mathrm{N}$ for 0.5 -ZIR, $850 \mathrm{~N}$ for 0.5 -LDC, 1'100 $\mathrm{N}$ for 0.5 -HYC and $1^{\prime} 950 \mathrm{~N}$ for 0.5 -COC. With CLD as the control, a significant difference was found between the groups 0.5 -COC and $0.5-\mathrm{LDC}(\mathrm{KW}: \mathrm{p}=0.0124)$. With PFM as the control, the comparisons between PFM and 0.5-LDC as well as between 0.5-COC and 0.5-LDC were significant $(\mathrm{KW}: \mathrm{p}=0.0026)$. Median F values of 2'493 $\mathrm{N}$ in the group 0.5-ZIR, 1'165 in the group 0.5 -LDC, 2'275 $\mathrm{N}$ in the group 0.5 -HYC and 2 '265 $\mathrm{N}$ in the group 0.5 -COC were found. The medians of the $\mathrm{F}$ values for the 1.0 thick restorations amounted of 2'100 $\mathrm{N}$ in 1.0-ZIR, 1'750 N in 1.0-LDC, 2'000 N in 1.0-HYC and 2'300 $\mathrm{N}$ in 1.0-COC. Testing the multiple comparisons with Dunn's method no significant differences were found ( $\mathrm{p}$ $>0.05)$. The median $\mathrm{F}$ values of the $1.0 \mathrm{~mm}$ thick restorations were: 2'489 $\mathrm{N}$ in the group 1.0-ZIR, 1'864 $\mathrm{N}$ in the group 1.0-LDC, 2'485 $\mathrm{N}$ in the group 1.0-HYC and 2'479 $\mathrm{N}$ in the group 1.0-COC. With CLD as the control group, a significant difference between zirconia and lithium-disilicate was found for the 0.5 $(\mathrm{p}=0.0017)$ and $1.0 \mathrm{~mm}(\mathrm{p}=0.0320)$ thick specimens. Comparing the $0.5 \mathrm{~mm}$ thick specimens with CLD as the control, a significant difference was found between 0.5-HYC and 0.5-LDC ( $\mathrm{p}=0.0017)$. With PFM as the control, the comparison of lithium disilicate and zirconia was statistically significant for both thicknesses ( $\mathrm{p}=0.0009$ for the $0.5 \mathrm{~mm}$ thick specimens; $\mathrm{p}=0.0074$ for the $1.0 \mathrm{~mm}$ thick specimens). In addition, with PFM as control group, significant differences were seen between 0.5-LDC and all other groups with restorations in $0.5 \mathrm{~mm}$ thickness $(\mathrm{p}=0.0017)$. CONCLUSIONS Regarding their maximum load-bearing capacity, minimally invasive occlusal veneers made of ceramic, hybrid materials or polymeric materials can be applied to correct occlusal tooth wear with exposed dentin and thus replace conventional crown restorations in cases of normally expected intraoral bite forces.
\end{abstract}

DOI: https://doi.org/10.1016/j.jmbbm.2019.04.006 
Posted at the Zurich Open Repository and Archive, University of Zurich

ZORA URL: https://doi.org/10.5167/uzh-171602

Journal Article

Accepted Version

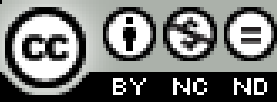

The following work is licensed under a Creative Commons: Attribution-NonCommercial-NoDerivatives 4.0 International (CC BY-NC-ND 4.0) License.

Originally published at:

Maeder, Mila; Pasic, Pavla; Ender, Adreas; Özcan, Mutlu; Benic, Goran I; Ioannidis, Alexis (2019). Loadbearing capacities of ultra-thin occlusal veneers bonded to dentin. Journal of the Mechanical Behavior of Biomedical Materials, 95:165-171.

DOI: https://doi.org/10.1016/j.jmbbm.2019.04.006 


\title{
Load-bearing capacities of ultra-thin occlusal veneers bonded to dentin
}

\author{
Maeder $\mathrm{M}^{* a}$, Pasic $\mathrm{P}^{* a}$, Adreas Ender $^{\mathrm{b}}$, Mutlu Özcan ${ }^{\mathrm{c}}$, Goran I. Benic ${ }^{\mathrm{c}}$, Alexis Ioannidis ${ }^{\mathrm{c}}$ \\ *: Equal contribution to the present investigation
}

Key words: ceramics, hybrid material, PICN, dental porcelain, resins, computer-aided design, computer-aided manufacturing, occlusal dental veneers, fatigue

\section{Address for correspondence:}

Dr. med. dent. Alexis loannidis

Clinic of Fixed and Removable Prosthodontics and

Dental Material Science

Center of Dental Medicine, University of Zurich

Plattenstrasse 11

$\mathrm{CH}-8032$ Zurich, Switzerland

Phone: +41446340404

Fax: +4144634 4305

E-mail: alexis.ioannidis@zzm.uzh.ch

\footnotetext{
a Doctoral student at the Clinic of Fixed and Removable Prosthodontics and Dental Material Science, Center of Dental Medicine, University of Zurich, Switzerland

${ }^{b}$ Clinic of Preventive Dentistry, Periodontology and Cariology, Center of Dental Medicine, University of Zurich, Switzerland

${ }^{c}$ Clinic of Fixed and Removable Prosthodontics and Dental Material Science, Center of Dental Medicine, University of Zurich, Switzerland
} 


\section{Abstract}

Objectives: To test whether the load-bearing capacity of occlusal veneers made of ceramic or hybrid materials bonded to dentin does differ from those of porcelain-fused-to metal or lithium disilicate glass ceramic crowns.

Material and methods: In 80 human molars, occlusal tooth substance was removed so that the defects extended into dentin, simulating defects caused by attrition/erosion. Restorations at a standardized thickness of either $0.5 \mathrm{~mm}$ or $1.0 \mathrm{~mm}$ were digitally designed. For both thicknesses, 4 test groups ( $n=10$ per group) were defined, each including a different restorative material: "0.5-ZIR": $0.5 \mathrm{~mm}$ thick zirconia (Vita YZ HT); "1.0-ZIR": $1.0 \mathrm{~mm}$ thick zirconia (Vita YZ HT); "0.5-LDC": $0.5 \mathrm{~mm}$ thick lithium disilicate ceramic (IPS e.max Press); "1.0-LDC": $1.0 \mathrm{~mm}$ thick lithium disilicate ceramic (IPS e.max Press); "0.5-HYC": $0.5 \mathrm{~mm}$ thick PICN (Vita Enamic); "1.0-HYC": $1.0 \mathrm{~mm}$ thick PICN (Vita Enamic); "0.5-COC": $0.5 \mathrm{~mm}$ thick tooth shaded resin composite (Lava Ultimate) and "1.0-COC": $1.0 \mathrm{~mm}$ thick tooth shaded resin composite (Lava Ultimate). Consecutively, the specimens were thermo-mechanically aged and then loaded until fracture. The load-bearing capacities $\left(F_{\max }\right)$ between the groups were statistically compared using the Kruskal-Wallis test $(p<0.05)$ and pairwise group comparison applying the Dunn's method. In addition, the results were compared to those of conventional lithium-disilicate ceramic crowns ("CLD") and to porcelainfused to metal crowns ("PFM").

Results: The median Finitial values for the $0.5 \mathrm{~mm}$ thin restorations were 1 '350 $\mathrm{N}$ for $0.5-\mathrm{ZIR}, 850 \mathrm{~N}$ for $0.5-\mathrm{LDC}, 1$ '100 N for $0.5-\mathrm{HYC}$ and 1 '950 N for 0.5-COC. With CLD as the control, a significant difference was found between the groups 0.5-COC and 0.5-LDC (KW: $p=0.0124)$. With PFM as the control, the comparisons between PFM and 0.5-LDC as well as between 0.5-COC and 0.5-LDC were significant (KW: $p=$ 0.0026). Median $F_{\max }$ values of 2'493 N in the group 0.5-ZIR, 1'165 in the group 0.5-LDC, 2'275 N in the group 0.5-HYC and 2'265 N in the group $0.5-\mathrm{COC}$ were found. The medians of the Finitial values for the 1.0 thick restorations amounted of 2'100 N in 1.0-ZIR, 1 '750 N in 1.0LDC, 2'000 N in 1.0-HYC and 2'300 N in 1.0-COC. Testing the multiple comparisons with Dunn's method no significant differences were found $(p>0.05)$. The median $F_{\max }$ values of the $1.0 \mathrm{~mm}$ thick restorations were: 2'489 $\mathrm{N}$ in the group 1.0-ZIR, 1'864 $\mathrm{N}$ in the group 1.0-LDC, 2'485 $\mathrm{N}$ in the group 1.0-HYC and 2'479 $\mathrm{N}$ in the group 1.0-COC. With CLD as the control group, a significant difference between zirconia and lithium-disilicate was found for the $0.5(p=0.0017)$ and $1.0 \mathrm{~mm}(p=0.0320)$ thick specimens. Comparing the $0.5 \mathrm{~mm}$ thick specimens with CLD as the control, a significant difference was found between 0.5-HYC and 0.5-LDC $(p=0.0017)$. With PFM as the control, the comparison of lithium disilicate and zirconia was statistically significant for both thicknesses $(p=0.0009$ for the 0.5 mm thick specimens; $p=$ 0.0074 for the $1.0 \mathrm{~mm}$ thick specimens). In addition, with PFM as control group, significant differences were seen between 0.5-LDC and all other groups with restorations in $0.5 \mathrm{~mm}$ thickness $(p=0.0017)$.

Conclusions: Regarding their maximum load-bearing capacity, minimally invasive occlusal veneers made of ceramic, hybrid materials or polymeric materials can be applied to correct occlusal tooth wear with exposed dentin and thus replace conventional crown restorations in cases of normally expected intraoral bite forces. 


\section{Introduction}

The number of teeth decayed by caries has significantly decreased during the industrialization of western countries (Jordan et al., 2014; Steiner et al., 2010). In contrary, the loss of tooth substance due to erosion is a common finding in the population of developed countries ( $\underline{\text { Schlueter and Luka, }}$ 2018). The reported prevalence in young patients is high and its progression with age can be expected (Bartlett et al., 2013; Jaeggi and Lussi, 2014). In order to compensate the loss of tooth substance caused by erosion, a prosthetic treatment may be indicated. Treatment concepts which propose the restoration of erosive tooth wear with full-crowns (Varma et al., 2018) require an additional and extensive preparation of the already hampered dentition (Edelhoff and Sorensen, 2002). Due to the potential biological complications of full-crown preparations such as vitality loss and need for endodontic treatment over time (Dahl, 1977; $\underline{\text { Pjetursson et al., 2007; Sailer et al., 2007; Valderhaug et }}$ al., 1997), these concepts nowadays may be replaced by less-invasive treatment strategies. For this purpose, the prosthetic rehabilitation applying a conservative preparation of the eroded teeth and using indirect minimally invasive approaches to restore them, have been suggested (Loomans et al., 2017).

As material for indirect minimally invasive treatment approaches glass ceramics are recommended (Muts et al., 2014). However, to use glass ceramic as a restorative material in the posterior area in reduced thicknesses may lead to a high rate of technical complications (Guess et al., 2013; Skouridou et al., 2013). Nowadays a vast amount of modified ceramic and hybrid-materials with altered mechanical properties have been introduced. These materials are claimed to overcome these technical problems and allow for restorations in reduced thicknesses. One strategy to optimize the mechanical performance of a restorative material, is to use a ceramic with a higher flexural strength and a higher fracture toughness in comparison to a conventional glass ceramic. Zirconia and lithium-disilicate are both restorative materials, which involve these properties (Christel et al., 1989; Elsaka and Elnaghy, 2016; Guazzato et al., 2004b; Miyazaki et al., 2013; Swain et al., 2016; Wagner and Chu, 1996). Another strategy to overcome the high rate of technical complications in thin restorations thicknesses is to combine the advantages known from ceramic and from polymer materials. For this reason, a 
hybrid material with a polymer-infiltrated ceramic network (PICN) was promoted (Awada and Nathanson, 2015; Swain et al., 2016). Furthermore, tooth-shaded resin composite materials for indirect reconstructions with a nanoparticle- and nanocluster-filled resin are available on the market (Awada and Nathanson, 2015).

Comparative studies, testing these reinforced ceramics, hybrid-materials and tooth shaded resin composite in thin restoration thicknesses are rare (Awada and Nathanson, 2015; Egbert et al., 2015; loannidis et al., 2018; Sieper et al., 2017). A previous study reported results of occlusal veneers bonded on enamel (loannidis et al., 2018). However, longevity of adhesion on to dentin as a consequence of aging could be anticipated to decrease over time (Breschi et al., 2008) which may decrease the survival of occlusal veneers. Therefore, the objective of this study was to test whether the load-bearing capacity of occlusal veneers made of these materials and bonded to dentin does differ from conventional preparations restored with porcelain-fused-to metal or lithium disilicate glass ceramic crowns. The hypothesis was that the load-bearing capacities would not be significantly different between the test- and the control-groups. 


\section{Material and Methods}

\subsection{Groups}

The test groups (Table 1) consisted of occlusal veneers fabricated out of different restorative materials (zirconia, lithium disilicate, PICN, tooth shaded resin composite) in the two different thicknesses (0.5 and $1.0 \mathrm{~mm}$ ) each. The subsequent groups were tested in 10 specimens per group: "0.5-ZIR"; "1.0ZIR"; "0.5-LDC"; “1.0-LDC"; "0.5-HYC"; "1.0-HYC"; "0.5-COC"; "1.0-COC". Two groups of 10 specimens each served as historical controls (loannidis et al., 2018) and contained of conventional crown preparations restored with CAD/CAM fabricated lithium-disilicate ceramic (“CLD”: IPS e.max CAD, Ivoclar Vivadent, Schaan, Liechtenstein) or porcelain-fused-to metal crowns ("PFM": Creation by Willy Geller; Manufacturer Klema, Meiningen, Austria / Esteticor Special; Cendres Metaux, Biel, Switzerland).

\subsection{Specimen preparation}

Eighty extracted intact human molars were embedded in a self-curing resin (Dura Lay; Reliance Dental Manufacturing LLC, Worth, IL, USA) inside a hollow cylinder. For the test groups, the occlusal surface was prepared in order to mimic substance defects due to attrition/erosion (Figure 1). For this purpose, the occlusal enamel of the molars was removed and the preparation was extended into dentin. After removal of the occlusal cusps, the level of dentin was further removed approximately $1 \mathrm{~mm}$ in direction of the pulp. In addition, sharp edges were rounded off. After preparation, the exposed central dentin was still surrounded by a margin of enamel. During the entire study procedures, the specimens were stored in deionized water. 


\section{Table 1}

Restorative materials used with their respective chemical composition.

\begin{tabular}{|c|c|c|c|}
\hline Group & $\begin{array}{l}\text { Restoration } \\
\text { thickness }\end{array}$ & Restorative material & Composition \\
\hline $0.5-Z I R$ & $0.5 \mathrm{~mm}$ & \multirow{3}{*}{$\begin{array}{l}\text { Yttria-stabilized tetragonal zirconia (Vita YZ HT; } \\
\text { Vita Zahnfabrik, Bad Säckingen, Germany) }\end{array}$} & \multirow{3}{*}{$\begin{array}{l}\mathrm{ZrO}_{2}(90.4-94.5 w t \%), \mathrm{Y}_{2} \mathrm{O}_{3}(4-6 \mathrm{wt} \%), \mathrm{HfO}_{2}(1.5-2.5 \mathrm{wt} \%), \mathrm{Al}_{2} \mathrm{O}_{3}(0-0.3 \mathrm{wt} \%), \mathrm{Er}_{2} \mathrm{O}_{3}(0-0.5 \mathrm{wt} \%), \mathrm{Fe}_{2} \mathrm{O}_{3}(0 \\
-0.3 \mathrm{wt} \%)\end{array}$} \\
\hline & & & \\
\hline 1.0-ZIR & $1.0 \mathrm{~mm}$ & & \\
\hline $0.5-\mathrm{LDC}$ & $0.5 \mathrm{~mm}$ & \multirow{3}{*}{$\begin{array}{l}\text { Lithium-disilicate ceramic (IPS e.max Press; } \\
\text { Ivoclar Vivadent, Schaan, Liechtenstein) }\end{array}$} & \multirow{3}{*}{$\begin{array}{l}\mathrm{SiO}_{2}(57-80 \mathrm{wt} \%), \mathrm{Li}_{2} \mathrm{O}(11-19 \mathrm{wt} \%), \mathrm{K}_{2} \mathrm{O}(0-13 \mathrm{wt} \%), \mathrm{P}_{2} \mathrm{O}_{5}(0-11 \mathrm{wt} \%), \mathrm{ZrO}_{2}(0-8 \mathrm{wt} \%), \mathrm{ZnO}(0-8 \mathrm{wt} \%) \text {, } \\
\text { other oxides and ceramic pigments }(0-10 \mathrm{wt} \%)\end{array}$} \\
\hline & & & \\
\hline 1.0-LDC & $1.0 \mathrm{~mm}$ & & \\
\hline $0.5-\mathrm{HYC}$ & $0.5 \mathrm{~mm}$ & \multirow[b]{2}{*}{$\begin{array}{l}\text { PICN (Vita Enamic; Vita Zahnfabrik, Bad } \\
\text { Säckingen, Germany) }\end{array}$} & \multirow[b]{2}{*}{$\begin{array}{l}\text { Polymer part (14 wt\%): UDMA; TEGDMA } \\
\text { Ceramic part }(86 \mathrm{wt} \%): \mathrm{SiO}_{2}(58-63 \%), \mathrm{Al}_{2} \mathrm{O}_{3}(20-23 \%), \mathrm{Na}_{2} \mathrm{O}(9-11 \%), \mathrm{K}_{2} \mathrm{O}(4-6 \%), \mathrm{B}_{2} \mathrm{O}_{3}(0.5-2 \%), \mathrm{ZrO}_{2}(< \\
1 \%), \mathrm{CaO}(<1 \%)\end{array}$} \\
\hline & & & \\
\hline $0.5-\mathrm{COC}$ & $0.5 \mathrm{~mm}$ & \multirow{3}{*}{$\begin{array}{l}\text { Tooth shaded resin composite (Lava Ultimate; } 3 \mathrm{M} \\
\text { ESPE, Seefeld, Germany) }\end{array}$} & \multirow{3}{*}{$\begin{array}{l}\text { Matrix: bis-GMA, UDMA, bis-EMA, TEGDMA } \\
\text { Filler: } 80 \text { wt } \% \text {, silica }(20 \mathrm{~nm}) \text {, zirconia }(4-11 \mathrm{~nm})\end{array}$} \\
\hline & & & \\
\hline $1.0-\mathrm{COC}$ & $1.0 \mathrm{~mm}$ & & \\
\hline
\end{tabular}




\section{Figure 1}

Schematic drawings of the test and control groups. In the test groups, the preparation extended into dentin, surrounded by a border of enamel. The restorations in the test groups consisted of either 0.5 or $1.0 \mathrm{~mm}$ thick occlusal veneers in different restorative materials (zirconia, lithium disilicate, PICN, tooth shaded resin composite). For the control groups, conventional crowns were prepared and the teeth restored with different restorative materials (lithium disilicate, porcelain-fused to metal).
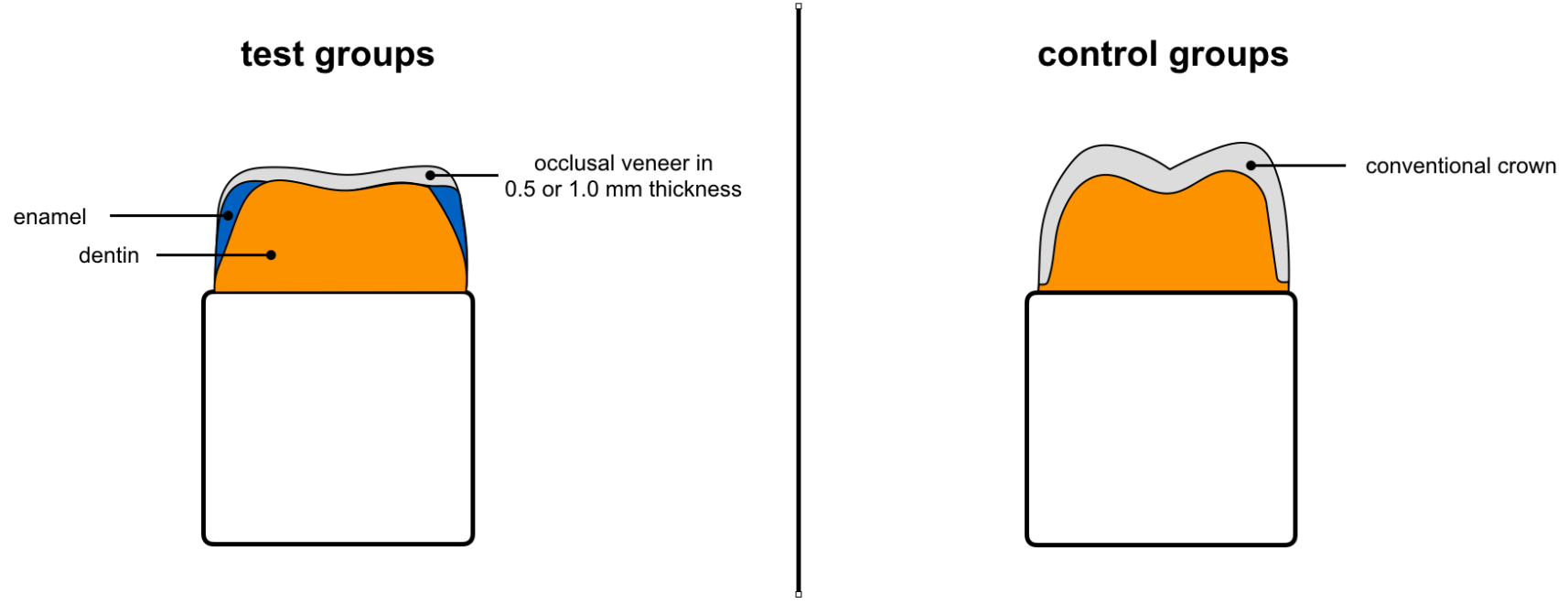


\subsection{Scanning procedures, restoration design and fabrication}

Digital impressions of the prepared teeth were made (Cerec Omnicam; Software-Version 4.4, Sirona, Bensheim, Germany) and transferred to a design software (InLab, Sirona). Depending on the group allocation, two different thicknesses were chosen for the design of the restorations being either 0.5 $\mathrm{mm}$ (range $0.3-0.7 \mathrm{~mm}$ ) or $1.0 \mathrm{~mm}$ (range $0.8-1.2 \mathrm{~mm}$ ). The method to standardize the restoration thickness was published recently elsewhere (loannidis et al., 2018).

The restorations for the groups $0.5-\mathrm{ZIR}, 1.0-\mathrm{ZIR}, 0.5-\mathrm{HYC}, 1.0-\mathrm{HYC}, 0.5-\mathrm{COC}$ and $1.0-\mathrm{COC}$ were directly milled out of the respective ingots using a 5-axis milling machine ( $\mathrm{MC} \mathrm{X} 5$; Sirona). For fabrication of the restorations in the groups $0.5-$ LDC and 1.0-LDC, first an acrylic template (Vita CAD Waxx; Vita Zahnfabrik) was milled out using the same milling machine. This template was consecutively used to produce pressed lithium-disilicate restorations (e.max Press; Ivoclar Vivadent) applying the "lost-wax and press-technique".

\subsubsection{Control groups CLD and PFM}

The historical control groups (loannidis et al., 2018), which were tested in the same series, consisted of 10 specimens in each group. The embedded molars where prepared according to conventional crown preparation guidelines with circular butt joint margins of $0.8-1.0 \mathrm{~mm}$ width, a tapering angle of 10-12 degrees, an occlusal reduction of $1.3-1.8 \mathrm{~mm}$ and a minimal abutment height of $3.0-4.0 \mathrm{~mm}$ (Figure 1).

As described for the test groups, the prepared specimens were digitized (Cerec Omnicam, Sirona) and the restorations were digitally designed (InLab, Sirona). The dimensions of the designed crowns were as follows: occlusal thickness $1.5 \mathrm{~mm}$, axial thickness $0.8-1.0 \mathrm{~mm}$.

The crowns of the CLD group were milled out of pre-fabricated blocks (IPS e.max CAD; Ivoclar Vivadent) using a 4-axis milling machine (MCXL; Sirona). Consecutively, the restorations were sintered to full density (Programat CS 2; Ivoclar Vivadent) according to the manufacturer's instructions. 
For the PFM group, the designed crowns were milled out of a prefabricated ingot (Vita CAD Wax; Vita Zahnfabrik) using a 4-axis milling machine (MCXL; Sirona). These acryl polymer restorations served as templates to form the shape of the prospective restorations. The porcelain-fused-to-metal crowns were directly manufactured on the prepared teeth (Creation by Willy Geller; Manufacturer Klema, Meiningen, Austria / Esteticor Special; Cendres Metaux, Biel, Switzerland).

\subsection{Cementation protocols}

All restorations were cemented according the manufacturer's instructions for the respective materials used in the different groups (Table 2).

\section{Table 2}

Cementation protocols for the used test-materials.

\begin{tabular}{|c|c|c|c|}
\hline Group & Applications steps on the tooth & Applications steps on the restoration & Cementation \\
\hline $\begin{array}{l}0.5-\mathrm{ZIR}, \\
1.0-\mathrm{ZIR}\end{array}$ & $\begin{array}{l}\text { 1. Apply } 35 \% \text { phosphoric acid (Ultraetch; Ultradent, Utah, } \\
\text { USA) to the prepared enamel surfaces for 30 s. } \\
\text { 2. Spray the surface with water for } 30 \mathrm{~s} \text { and consecutively } \\
\text { gently air-dry. } \\
\text { 3. Mix the two agents } 1: 1 \text { (ED Primer A and B; Kuraray, } \\
\text { Tokyo, Japan) for 3-5s and apply the mixture for } 60 \text { s on } \\
\text { the enamel, consecutively gently air-dry and light-cure } \\
\text { for } 30 \text { seconds. }\end{array}$ & $\begin{array}{l}\text { 1. Air-abrade the inner surface of the tabletop (CoJet } 50 \mu \mathrm{mm} 1.2 \mathrm{bar} ; 3 \mathrm{M} \mathrm{ESPE} \text { ) for } 15 \mathrm{~s} \\
\text { and consecutively gently air-dry. } \\
\text { 2. Apply the agent (Clearfi Ceramic Primer; Kuraray, Tokyo, Japan) for } 5 \mathrm{~s} \text {, consecutively } \\
\text { gently air-dry. }\end{array}$ & $\begin{array}{l}\text { 1. Mix the adhesive cement } 1: 1 \text { (Panavia 21; Kuraray) für } 20 \mathrm{~s} \text {, apply on the restoration. } \\
\text { 2. Apply and leave glycering gel (Oxygard; Kuraray) on the edge of the restoration for } 7 \text { min } \\
\text { before removing the gel with water-spray. }\end{array}$ \\
\hline $\begin{array}{l}0.5-\text { LDC, } \\
1.0 \text {-LDC }\end{array}$ & $\begin{array}{l}\text { 1. Apply } 35 \% \text { phosphoric acid (Ultraetch; Ultradent, Utah, } \\
\text { USA) to the prepared enamel surfaces for } 30 \mathrm{~s} \text {. } \\
\text { 2. Spray the surfice with water for } 30 \mathrm{~s} \text { and consecutively } \\
\text { gently air-dry. } \\
\text { 3. Apply the bonding agent (Heliobond; Ivoclar Vivadent) } \\
\text { and consecutively gently air-dry (no light-cure). }\end{array}$ & $\begin{array}{l}\text { 1. Apply } 5 \% \text { hydrofluoric acid for } 20 \mathrm{~s} \text { (Ivoclar Vivadent). } \\
\text { 2. Spray the surface with water for } 60 \mathrm{~s} \text {. } \\
\text { 3. Apply the silane (Monobond Plusadent) for } 60 \mathrm{~s} \text {, before gently air-drying. } \\
\text { 4. Apply the bonding agent (Heliobond; Ivoclar Vivadent) and consecutively gently air-dry } \\
\text { (no light-cure). }\end{array}$ & $\begin{array}{l}\text { 1. Apply the adhesive cement, mix } 1: 1 \text { (Variolink II; Ivoclar Vivadent) on the restoration. } \\
\text { 2. Remove excess cement carefully before light-curing for } 6 \times 40 \mathrm{~s} \text {. }\end{array}$ \\
\hline $\begin{array}{l}0.5-\mathrm{HYC}, \\
1.0-\mathrm{HYC}\end{array}$ & $\begin{array}{l}\text { 1. Apply } 35 \% \text { phosphoric acid (Ultraetch; Ultradent, Utah, } \\
\text { USA) to the prepared enamel surfaces for } 30 \mathrm{~s} \text {. } \\
\text { 2. Spray the surface with water for } 30 \mathrm{~s} \text { and consecutively } \\
\text { gently air-dry. } \\
\text { 3. Apply the bonding agent (Heliobond; Ivoclar Vivadent) } \\
\text { and consecutively gently air-dry (no light-cure). }\end{array}$ & $\begin{array}{l}\text { 1. Apply } 5 \% \text { hydrofluoric acid for } 60 \mathrm{~s} \text { (Ivoclar Vivadent). } \\
\text { 2. Spray the surface with water for } 0 \mathrm{~s} \text {. } \\
\text { 3. Apply the silane (Monobond Plus; Ivolar Vivadent) for } 60 \mathrm{~s} \text {, before gently air-drying. } \\
\text { 4. Appply the bonding agent (Heliobond; Ivoclar Vivadent) and consecutively gently air-dry } \\
\text { (no light-cure). }\end{array}$ & $\begin{array}{l}\text { 1. Apply the adhesive cement, mix } 1: 1 \text { (Tetric Flow; Ivoclar Vivadent) on the restoration. } \\
\text { 2. Remove excess cement carefully before light-curing for } 6 \times 40 \mathrm{~s} \text {. }\end{array}$ \\
\hline $\begin{array}{l}0.5-\mathrm{COC}, \\
1.0-\mathrm{COC}\end{array}$ & $\begin{array}{l}\text { 1. Apply } 35 \% \text { phosphoric acid (Ultraetch; Ultradent, Utah, } \\
\text { USA) to the prepared enamel surfaces for } 30 \mathrm{~s} \text {. } \\
\text { 2. Spray the surface with water for } 30 \mathrm{~s} \text { and consecutively } \\
\text { gently air-dry. } \\
\text { 3. Apply the bonding agent (Scotchbond Universal } \\
\text { Adhesive; } 3 \mathrm{M} \text { ESPE) on the tooth for } 20 \mathrm{~s} \text {, consecutively } \\
\text { gently air-dry for } 5 \mathrm{~s} \text { (no light-cure). }\end{array}$ & $\begin{array}{l}\text { 1. Air-abrade the inner surface of the tabletop (CoJet } 50 \mu \mathrm{m} 1.2 \mathrm{bar} ; 3 \mathrm{M} \text { ESPE) for } 15 \mathrm{~s} \\
\text { and consecutively gently air-dry. } \\
\text { 2. Apply the bonding agent (Scotchbond Universal Adhesive; } 3 \mathrm{M} \text { ESPE) on the inner } \\
\text { surface of the table top for } 20 \mathrm{~s} \text {, consecutively gently air-dry for } 5 \mathrm{~s} \text { (no light-cure). } \\
\end{array}$ & $\begin{array}{l}\text { 1. Apply the adhesive cement (RelyX Ultimate cement, } 3 \mathrm{M} \mathrm{ESPE} \text { ) on the restoration. } \\
\text { 2. Remove excess cement carefully and light-cure for } 3 \times 30 \mathrm{~s} \text {. }\end{array}$ \\
\hline
\end{tabular}




\subsection{Aging procedures}

The specimens were aged in a custom-made chewing simulator (Krejci et al., 1990) applying thermocycling $\left(5-50^{\circ} \mathrm{C}\right.$, dwelling time $\left.120 \mathrm{~s}\right)$ and chewing simulation (1'200'000 cycles, $49 \mathrm{~N}$ force and 1.67 $\mathrm{Hz}$ loading frequency). As antagonist with a vertical indenter movement of $1 \mathrm{~mm}$, a corrosion-free steel indenter with a rounded polished tip ( $\varnothing 8 \mathrm{~mm}$ ) was used to load the specimens in axial direction to the occlusal plane. The integrity of the specimens after aging procedures was controlled under a stereomicroscope at a $1.25 \times$ magnification.

\subsection{Static loading}

The specimens were further investigated performing a static fracture load test using a universal testing machine (Zwick / Roell Z010; Zwick, Ulm, Germany). The indenter exposed force to the occlusal surface in a perpendicular direction with a crosshead speed of $1 \mathrm{~mm} / \mathrm{min}$ until fracture of the specimen. The force needed to crack the specimen was recorded $\left(F_{\text {initial }}\right)$ and the load, which was registered as soon as fracture load decreased by $20 \%$ of the maximum load $\left(F_{\max }\right)$.

On digital photographs and with loupes at a magnification of $2.5 \times$, the failures were categorized into 4 scores: score $0=$ no visible fracture, score $1=$ cohesive fracture within the restoration, score $2=$ cohesive fracture of the restoration and of the cement layer, score $3=$ fracture of the restorationcement-tooth complex.

\subsection{Statistical analysis}

The metric variables with mean, median, standard deviations, quartiles, minimum and maximum were described. Categorical variables were summarized by counts and proportions of the categories based on the material types and thickness. The comparisons of the group medians of the metric variables were performed with nonparametric methods (Kruskal-Wallis test). Multiple comparisons of two groups are based on adjusted p-values, using the method of Dunn (Bonferroni). The proportions of the categorical parameters with the chi-squares test were compared. P-values $<0.05$ were considered to be statistically significant in all tests. 


\section{Results}

It has to be stated that for the group 0.5 -ZIR only 4 out 10 restorations could be fabricated and tested due to problems in reliably manufacturing the zirconia specimens.

\subsection{Fatigue resistance}

All tested specimens survived the thermo-mechanical aging procedures.

\subsection{Load-bearing capacity}

\subsubsection{Restorations with $0.5 \mathrm{~mm}$ thickness}

The median $F_{\text {initial }}$ values were 1'350 $\mathrm{N}$ for $0.5-\mathrm{ZIR}, 850 \mathrm{~N}$ for $0.5-\mathrm{LDC}, 1$ '100 $\mathrm{N}$ for $0.5-\mathrm{HYC}$ and 1'950 $\mathrm{N}$ for $0.5-\mathrm{COC}$ (Table 3, Figure 2). With CLD as the control, a significant difference was found between the groups $0.5-\mathrm{COC}$ and $0.5-\mathrm{LDC}$ (KW: $\mathrm{p}=0.0124,5$ groups). With PFM as the control, the comparisons between PFM and 0.5-LDC as well as between 0.5-COC and 0.5-LDC were significant $(\mathrm{KW}: \mathrm{p}=0.0026,5$ groups $)$.

The following median $F_{\max }$ values were found: 2'493 $\mathrm{N}$ for 0.5-ZIR, 1'165 $\mathrm{N}$ for 0.5-LDC, 2'275 $\mathrm{N}$ for 0.5-HYC and 2'265 $\mathrm{N}$ for 0.5-COC (Table 3, Figure 3). Using CLD as the control group, a significant difference between $0.5-$ ZIR and $0.5-$ LDC as well as between $0.5-H Y C$ and $0.5-$ LDC was found (KW: $p$ $=0.0022,5$ groups). Taking PFM as the control, the Kruskal-Wallis test $(p=0.0009,5$ groups) was significant between the group 0.5-LDC and the groups 0.5-COC, 0.5-HYC, 0.5-ZIR and PFM.

\subsubsection{Restorations with $1.0 \mathrm{~mm}$ thickness}

The median of the $F_{\text {initial }}$ values for the 1.0 thick restorations amounted of 2'100 N in 1.0-ZIR, 1'750 N in 1.0-LDC, $2{ }^{\prime} 000 \mathrm{~N}$ in 1.0-HYC and 2'300 $\mathrm{N}$ in 1.0-COC (Table 3, Figure 2). The Kruskal-Wallis test detected significant differences with CLD (KW: $p=0.0209,5$ groups) or PFM (KW: $p=0.0156,5$ groups) as controls. However, the multiple comparisons with Dunn's method did not show any significant differences $(p>0.05)$. 
The respective medians for the $F_{\max }$ values for the 1.0 thick restorations were 2 ' $489 \mathrm{~N}$ for $1.0-\mathrm{ZIR}$, 1'864 $\mathrm{N}$ for 1.0-LDC, 2'485 $\mathrm{N}$ for 1.0-HYC and 2'479 $\mathrm{N}$ for 1.0-COC (Table 3, Figure 3). With CLD as the control, the differences between the group 1.0-LDC and 1.0-ZIR were significant (KW: $p=0.03205$ groups). With PFM as control the group, the Kruskall-Wallis test ( $p=0.0074,5$ groups) found significant different medians. Applying the Dunn's method, the difference between 1.0-LDC and 1.0-ZIR was significant $(p<0.05)$. 


\section{Table 3}

The force required to crack the material $\left(F_{\text {initial }}\right)$ and the load-bearing capacity $\left(F_{\max }\right)$ in Newton for all groups under investigation with mean, standard deviation (SD), first quartile (Q1), median, third quartile (Q3), minimum and maximum.

\begin{tabular}{|c|c|c|c|c|c|c|c|c|c|c|c|c|}
\hline & \multirow[b]{2}{*}{$\mathrm{n}$} & \multirow[b]{2}{*}{ group } & \multicolumn{5}{|l|}{ F initial } & \multicolumn{5}{|l|}{$F \max$} \\
\hline & & & Mean \pm SD & Q1 & Median & Q3 & ge $\min$ to $\max$ & Mean \pm SD & Q1 & Median & Q3 & ge $\min$ to $\max$ \\
\hline \multirow{4}{*}{$\begin{array}{l}0.5 \mathrm{~mm} \text { thick } \\
\text { restorations }\end{array}$} & 4 & $0.5-Z I R$ & $1425 \pm 359$ & 1150 & 1350 & 1700 & 1100 to 1900 & $2382 \pm 228$ & 2265 & 2493 & 2499 & 2039 to 2502 \\
\hline & 10 & 0.5 -LDC & $845 \pm 320$ & 500 & 850 & 1100 & 450 to 1300 & $1191 \pm 382$ & 846 & 1165 & 1581 & 578 to 1703 \\
\hline & 10 & $0.5-\mathrm{HYC}$ & $1415 \pm 569$ & 1000 & 1100 & 2000 & 800 to 2400 & $1981 \pm 617$ & 1395 & 2275 & 2494 & 976 to 2499 \\
\hline & 10 & $0.5-\mathrm{coc}$ & $1752 \pm 695$ & 1400 & 1950 & 2300 & 220 to 2400 & $2092 \pm 439$ & 1617 & 2265 & 2488 & 1439 to 2495 \\
\hline \multirow[t]{4}{*}{$\begin{array}{l}1.0 \mathrm{~mm} \text { thick } \\
\text { restorations }\end{array}$} & 10 & 1.0-ZIR & $2135 \pm 245$ & 1900 & 2100 & 2400 & 1800 to 2400 & $2483 \pm 23$ & 2485 & 2489 & 2491 & 2418 to 2497 \\
\hline & 10 & 1.0-LDC & $1690 \pm 580$ & 1200 & 1750 & 2100 & 600 to 2400 & $1851 \pm 631$ & 1291 & 1864 & 2485 & 767 to 2489 \\
\hline & 10 & 1.0-HYC & $1590 \pm 542$ & 1100 & 2000 & 2000 & 800 to 2000 & $2239 \pm 493$ & 2163 & 2485 & 2491 & 902 to 2495 \\
\hline & 10 & $1.0-\mathrm{COC}$ & $2160 \pm 306$ & 2000 & 2300 & 2400 & 1600 to 2400 & $2328 \pm 288$ & 2170 & 2479 & 2490 & 1613 to 2494 \\
\hline
\end{tabular}


Figure 2

Box-plots for the $F_{\text {initial }}$ values of the test groups 0.5-ZIR, 1.0-ZIR, 0.5-LDC, 1.0-LDC, 0.5-HYC, 1.0HYC, 0.5-COC and 1.0-COC. The medians of the groups CLD and PFM were used as controls. Significant differences $(\mathrm{KW} \mathrm{p}<0.05)$ between the groups are marked with a dashed red bar.

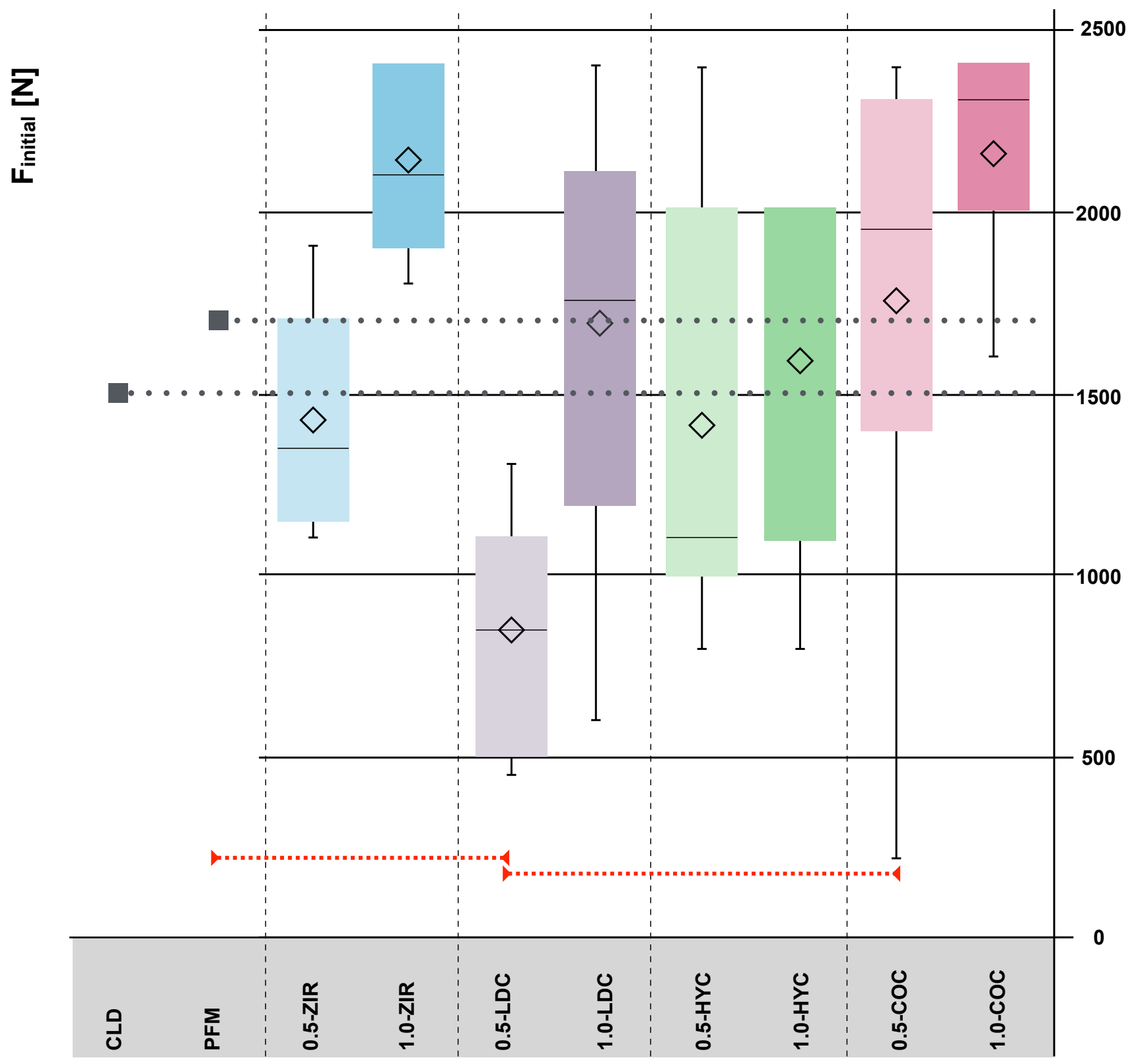


Figure 3

Box-plots for the $F_{\max }$ values of the test groups $0.5-\mathrm{ZIR}, 1.0-\mathrm{ZIR}, 0.5-\mathrm{LDC}, 1.0-\mathrm{LDC}, 0.5-\mathrm{HYC}, 1.0-$ HYC, 0.5-COC and 1.0-COC. The medians of the groups CLD and PFM were used as controls. Significant differences $(\mathrm{KW} \mathrm{p}<0.05)$ between the groups are marked with a dashed red bar.

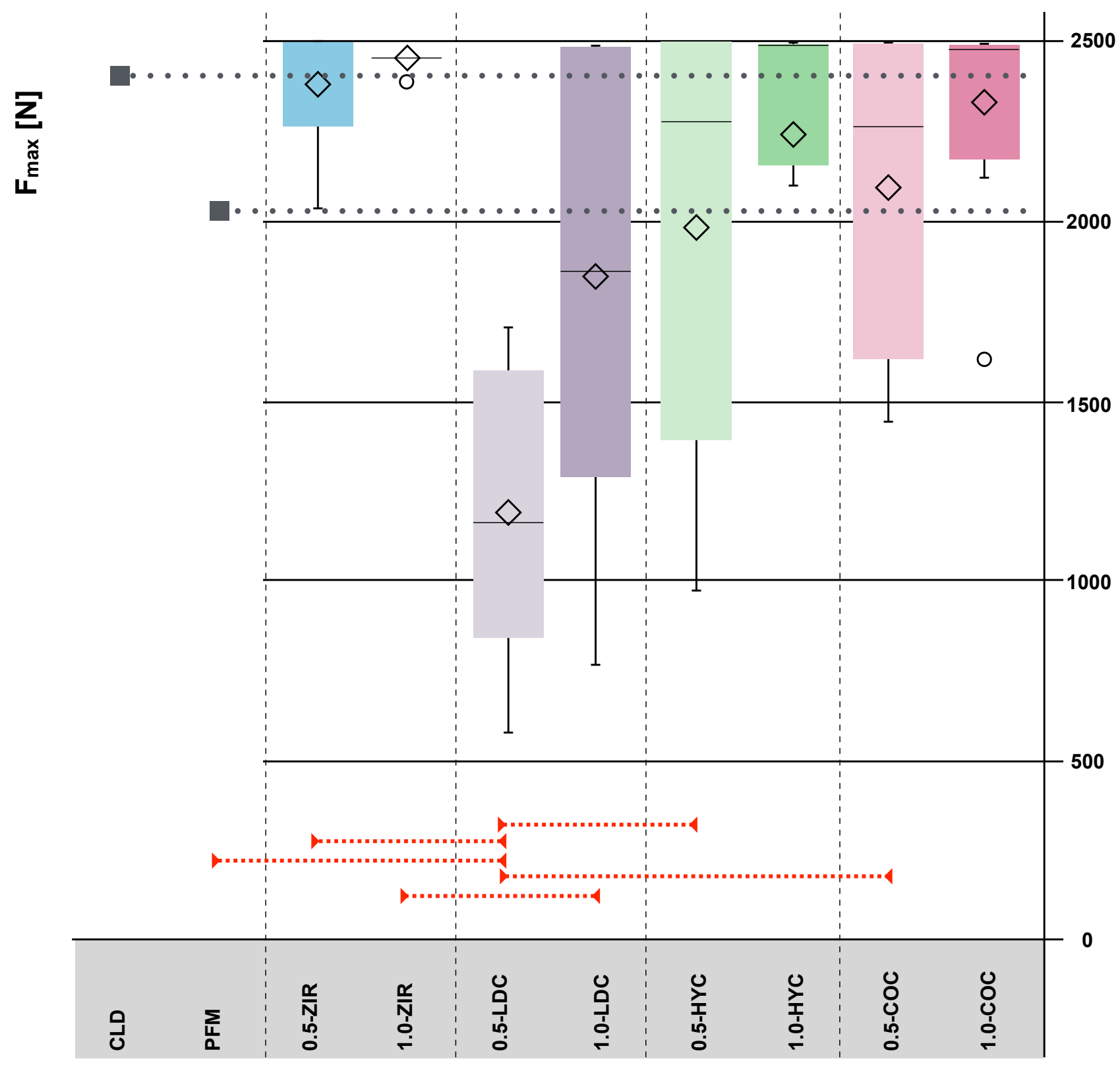




\subsection{Failure types}

The Chi-squares tests comparing the failure types of the control and test groups (Table 4) showed no statistically significant differences, neither for the $0.5 \mathrm{~mm}$ thin specimens $(p=0.7779)$ nor for the 1.0 $\mathrm{mm}$ thick specimens $(p=0.1476)$.

\section{Table 4}

Failure types with percentage of no visible fracture (score 0), cohesive fracture within the restoration (score 1), cohesive fracture of the restoration and of the cement layer (score 2) and fracture of the restoration-cement-tooth complex (score 3).

\begin{tabular}{|l|c|c|c|c|}
\hline Group & \multicolumn{1}{|c}{ Score 0 [\%] } & Score 1 [\%] & \multicolumn{1}{c|}{ Score 2 [\%] } & Score 3 [\%] \\
\hline 0.5-ZIR & 0 & 0 & 100 & 0 \\
\hline 0.5-LDC & 0 & 0 & 100 & 0 \\
\hline 0.5-HYC & 10 & 10 & 70 & 10 \\
\hline 0.5-COC & 0 & 10 & 90 & 0 \\
\hline 1.0-ZIR & 20 & 0 & 80 & 0 \\
\hline 1.0-LDC & 0 & 20 & 70 & 10 \\
\hline 1.0-HYC & 0 & 40 & 50 & 10 \\
\hline 1.0-COC & 20 & 0 & 70 & 0 \\
\hline
\end{tabular}




\section{Discussion}

In the present investigation, no complications or failures in any of the tested materials occurred during the aging phase, meaning that all materials withstood the thermo-mechanical aging which simulates dynamic loading forces under clinical conditions. The load-bearing capacities of the $1.0 \mathrm{~mm}$ thick minimally invasive occlusal veneers in the different tested materials were found to be not different to the ones of the control materials representing conventional treatment concepts. Using the test materials in a thickness of $0.5 \mathrm{~mm}$ this applies for all materials expect for lithium disilicate. The outcomes for lithium disilicate were significantly inferior when compared to the other tested groups.

During mastication, teeth and restored teeth must resist cyclic loads and temperature changes in the wet oral cavity. In order to simulate physiological conditions, the dynamic fatigue and the temperature alterations were simulated with a chewing simulator under wet conditions. In total 1'200'000 cycles of dynamic loading were applied, which is reported in literature to simulate 5 years of clinical service (Bates et al., 1975; DeLong and Douglas, 1991; Steiner et al., 2009). To mimic conditions during normal chewing function and swallowing, a load of $49 \mathrm{~N}$ was applied at $1.67 \mathrm{~Hz}$ loading frequency. The applied aging procedure did not lead to any failure of the tested restorations. Thus, this implies that the tested minimally invasive occlusal veneers bonded to dentin and made out of zirconia, lithiumdisilicate, PICN or tooth shaded resin material can withstand normal clinical conditions irrespective of the restoration thickness. Normal masticatory forces however, can reach higher values than $49 \mathrm{~N}$. In the posterior region they can range from 200 to $540 \mathrm{~N}$ and even raise up to $800 \mathrm{~N}$ in patients with bruxism (Bates et al., 1976). Taking this into consideration, one has to pay attention on the values which are achieved by static loading tests. The median $F_{\text {initial }}$ values for the $0.5 \mathrm{~mm}$ thick specimens were at least $850 \mathrm{~N}$, which is supposed to be higher than extreme masticatory loading forces. By increasing the restoration thickness to $1.0 \mathrm{~mm}$, the median $F_{\text {initial }}$ values were at least 1'750 $\mathrm{N}$, which is by far higher than expected under extreme clinical conditions. Looking at the minimum values of the forces which were required to crack the specimens, some materials showed values beneath these $800 \mathrm{~N}$. Occlusal veneers made out of lithium disilicate formed cracks starting at $450 \mathrm{~N}$ in a thickness 
of $0.5 \mathrm{~mm}$ and at $600 \mathrm{~N}$ in a thickness of $1.0 \mathrm{~mm}$. Testing the specimens which used the tooth shaded resin material as restorative material for the occlusal veneers, the crack formation started at $220 \mathrm{~N}$ for the $0.5 \mathrm{~mm}$ thick specimens. This may indicate that these two materials are not ideal to restore patients in which high loading forces can be expected and an alternative material selection should be considered. In contrary, for zirconia the minimal forces which are required to form cracks within the material were $1 ' 100 \mathrm{~N}$. For PICN, the minimal forces were $800 \mathrm{~N}$, which is in accordance to another study revealing failures in PICN-crowns only at very high loads (El Zhawi et al., 2016). Thus, it is assumed that these materials are supposed to withstand high masticatory forces.

When comparing the $F_{\text {initial }}$ and $F_{\max }$ values of the minimally invasive treatment concepts to the conventional treatment concepts, differences were found only between the test material lithium disilicate in a thickness of $0.5 \mathrm{~mm}$ and the control group with the porcelain-fused to metal crowns. These results contradict recently published data, where no differences were found between the 0.5 $\mathrm{mm}$ thick lithium disilicate occlusal veneers and the same control (loannidis et al., 2018). Whereas in the present investigation the occlusal veneers were bonded to dentin, in the mentioned study occlusal veneers of $0.5 \mathrm{~mm}$ thickness were bonded to enamel. In tendency, lithium-disilicate restorations bonded to enamel show higher fracture resistances than those having dentin as substrate (Clausen et al., 2010). This was found in a study evaluating the influence on the masticatory fatigue and the fracture resistance of restorations bonded either to enamel or to dentin (Clausen et al., 2010). Similar to the present study, all specimens survived the aging procedures irrespective of the bonding substrate (Clausen et al., 2010). The median fracture resistances of the restorations bonded to dentin however, amounted 3'840 N, whereas the specimens having enamel as a bonding substrate reached values of 4'173 $\mathrm{N}$ (Clausen et al., 2010). In contrast to the $0.5 \mathrm{~mm}$ thick lithium disilicate restorations, the $1 \mathrm{~mm}$ thick occlusal veneers showed no differences compared to the control groups. A study tested the influence of the thickness of lithium disilicate occlusal veneers on the median fracture resistance (Sasse et al., 2015). It was shown that the ceramic thickness has an influence on the mean fracture resistance (Sasse et al., 2015). The respective values were 2'370 N for a thickness of $0.3-0.6 \mathrm{~mm}$ and 3'000 $\mathrm{N}$ for occlusal veneers in a thickness of $0.7-1.0 \mathrm{~mm}$ (Sasse et al., 2015). The authors 
suggested that a minimum thickness of $0.7-1.0 \mathrm{~mm}$ is necessary to restore teeth with pressed lithium disilicate occlusal veneers (Sasse et al., 2015).

The significantly lower $F_{\text {initial }}$ and $F_{\max }$ values of the lithium disilicate reconstructions in comparison to the values obtained in the group with the porcelain-fused to metal crowns are unexpected for an additional reason. Normally, monolithic reconstructions achieve higher values than manually veneered crowns as they come along with more favorable mechanical properties (Guazzato et al., 2004a). This is due to the high rate of edge chipping in manually layered ceramic structures which as a consequence should result in low $\mathrm{F}_{\text {initial }}$ values (Ozcan and Niedermeier, 2002; Raigrodski et al., 2012). In this regard, monolithic reconstructions as in the case of zirconia and lithium disilicate usually deliver more favorable outcomes which could be confirmed for monolithic zirconia in this study.

The inherent mechanical properties of the materials tested in this study, did not necessarily correlate to the final load-bearing capacity. Normally, the tested materials show evident variations in terms of fracture strength and fracture toughness. In this context, the highest values usually are measured when zirconia as a restorative material is tested (Denry and Kelly, 2008; Guazzato et al., 2004b). These values are followed by the ones obtained by lithium disilicate, hybrid materials and polymeric materials (Della Bona et al., 2014; Guazzato et al., 2004a; Porto et al., 2018). The missing correlation between the normally achieved fracture strength and fracture toughness values and the load-bearing capacities found in this study, could be attributed to the adhesion properties of the luting cement bonded to the dentinal substrate and the occlusal veneer material. In the present investigation not the mechanical property of the restorative material itself, but the entire tooth-cement-restoration complex was tested. As crack formation usually starts from the zone of cementation, a proper adhesion of the restoration to the tooth is crucial and dictates the longevity of adhesion and thus the load-bearing capacity (Zhang et al., 2009). In this context it has to be mentioned that polymeric materials are known to come along with

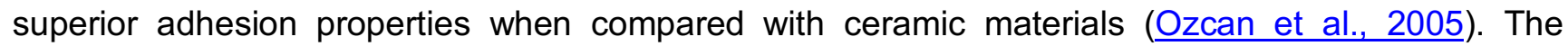
adhesion between the restorative material and the tooth could compensate the individual inferior mechanical properties of some of the tested materials (Ozcan et al., 2005; Ozcan et al., 2007). The reason for the higher median $\mathrm{F}_{\max }$ values obtained for polymeric or hybrid materials when compared to 
lithium disilicate, could be explained on these grounds. Contrary to the previous report (Breschi et al., 2008), adhesion to dentin was not a limiting factor for the longevity of occlusal veneers tested in this study.

Load-to-fracture tests has been previously criticized (Kelly et al., 2012). In this context, the type of test employed in this study has certain limitations. Thus, contact stresses measurements at the wear facets and finite element analyses and damage mechanics should be further investigated in future studies. One other aspect which requires further studies is the variation of the luting cement type. In this study, based on the best available knowledge, conditioning methods and the cement type were selected in conjunction with the corresponding material tested. From adhesion perspective to the reconstruction material, this approach could be considered appropriate. However, some of the selected cements may present less favorable adhesion on the dentin which could be further investigated (Ozcan and Mese, $\underline{2012)}$. 


\section{Conclusions}

Regarding their load-bearing capacity minimally invasive occlusal veneers made of zirconia, lithiumdisilicate, PICN or tooth shaded resin composite can be recommended to restore worn teeth with exposed dentin and thus replace conventional treatment concepts with full crown restorations. Minimum load-bearing capacities all exceed the normally expected intraoral bite forces. Clinicians should note that occlusal veneers in a thickness of $0.5 \mathrm{~mm}$ and made out of zirconia are difficult to fabricate which may limit their clinical indication for ultra-thin reconstructions. 


\section{Conflict of Interest}

This study was mainly financially supported by the Clinic for Fixed and Removable Prosthodontics and Dental Material Science, Center of Dental Medicine, University of Zurich, Zurich, Switzerland. The Swiss Society for Reconstructive Dentistry (SSRD) supported this investigation in parts with a research grant (\#2017_1a). The authors acknowledge the material support from Vita Zahnfabrik, Ivoclar Vivadent and 3M ESPE. 


\section{Acknowledgements}

The authors express their special thanks to Albert Trottmann, Pascal Müller and Tonino Di Bellofor their valuable help during fabrication of the specimen and Prof. Jürg Hüsler for the statistical analysis. 


\section{References}

Awada, A., Nathanson, D., 2015. Mechanical properties of resin-ceramic CAD/CAM restorative materials. J. Prosthet. Dent. 114, 587-593.

Bartlett, D.W., Lussi, A., West, N.X., Bouchard, P., Sanz, M., Bourgeois, D., 2013. Prevalence of tooth wear on buccal and lingual surfaces and possible risk factors in young European adults. J. Dent. 41, 1007-1013.

Bates, J.F., Stafford, G.D., Harrison, A., 1975. Masticatory function--a review of the literature. 1. The form of the masticatory cycle. J. Oral Rehabil. 2, 281-301.

Bates, J.F., Stafford, G.D., Harrison, A., 1976. Masticatory function - a review of the literature. III. Masticatory performance and efficiency. J. Oral Rehabil. 3, 57-67.

Breschi, L., Mazzoni, A., Ruggeri, A., Cadenaro, M., Di Lenarda, R., De Stefano Dorigo, E., 2008. Dental adhesion review: aging and stability of the bonded interface. Dent. Mater. 24, 90-101.

Christel, P., Meunier, A., Heller, M., Torre, J.P., Peille, C.N., 1989. Mechanical properties and shortterm in-vivo evaluation of yttrium-oxide-partially-stabilized zirconia. J. Biomed. Mater. Res. 23, 45-61.

Clausen, J.O., Abou Tara, M., Kern, M., 2010. Dynamic fatigue and fracture resistance of nonretentive all-ceramic full-coverage molar restorations. Influence of ceramic material and preparation design. Dent. Mater. 26, 533-538.

Dahl, B.L., 1977. Dentine/pulp reactions to full crown preparation procedures. J. Oral Rehabil. 4, 247254.

Della Bona, A., Corazza, P.H., Zhang, Y., 2014. Characterization of a polymer-infiltrated ceramicnetwork material. Dent. Mater. 30, 564-569.

DeLong, R., Douglas, W.H., 1991. An artificial oral environment for testing dental materials. IEEE Trans. Biomed. Eng. 38, 339-345.

Denry, I., Kelly, J.R., 2008. State of the art of zirconia for dental applications. Dent. Mater. 24, 299307.

Edelhoff, D., Sorensen, J.A., 2002. Tooth structure removal associated with various preparation designs for posterior teeth. Int. J. Periodontics Restorative Dent. 22, 241-249.

Egbert, J.S., Johnson, A.C., Tantbirojn, D., Versluis, A., 2015. Fracture strength of ultrathin occlusal veneer restorations made from CAD/CAM composite or hybrid ceramic materials. Oral Sci Int 12, 5358. 
El Zhawi, H., Kaizer, M.R., Chughtai, A., Moraes, R.R., Zhang, Y., 2016. Polymer infiltrated ceramic network structures for resistance to fatigue fracture and wear. Dent. Mater. 32, 1352-1361.

Elsaka, S.E., Elnaghy, A.M., 2016. Mechanical properties of zirconia reinforced lithium silicate glassceramic. Dent. Mater. 32, 908-914.

Guazzato, M., Albakry, M., Ringer, S.P., Swain, M.V., 2004a. Strength, fracture toughness and microstructure of a selection of all-ceramic materials. Part I. Pressable and alumina glass-infiltrated ceramics. Dent. Mater. 20, 441-448.

Guazzato, M., Albakry, M., Ringer, S.P., Swain, M.V., 2004b. Strength, fracture toughness and microstructure of a selection of all-ceramic materials. Part II. Zirconia-based dental ceramics. Dent. Mater. 20, 449-456.

Guess, P.C., Selz, C.F., Steinhart, Y.N., Stampf, S., Strub, J.R., 2013. Prospective clinical splitmouth study of pressed and CAD/CAM all-ceramic partial-coverage restorations: 7-year results. Int. J. Prosthodont. 26, 21-25.

Ioannidis, A., Mühlemann, S., Özcan, M., Hüsler, J., Hämmerle, C.H., Benic, G., 2018. Ultra-thin occlusal veneers bonded to enamel and made of ceramic or hybrid materials exhibit load-bearing capacities not different from conventional restorations. Journal of the mechanical behavior of biomedical materials.

Jaeggi, T., Lussi, A., 2014. Prevalence, incidence and distribution of erosion. Monogr. Oral Sci. 25, 55-73.

Jordan, R.A., Bodechtel, C., Hertrampf, K., Hoffmann, T., Kocher, T., Nitschke, I., Schiffner, U., Stark, H., Zimmer, S., Micheelis, W., Group, D.V.S.I., 2014. The Fifth German Oral Health Study (Funfte Deutsche Mundgesundheitsstudie, DMS V) - rationale, design, and methods. BMC Oral Health 14, 161.

Kelly, J.R., Benetti, P., Rungruanganunt, P., Bona, A.D., 2012. The slippery slope: critical perspectives on in vitro research methodologies. Dent. Mater. 28, 41-51.

Krejci, I., Reich, T., Lutz, F., Albertoni, M., 1990. [An in vitro test procedure for evaluating dental restoration systems. 1. A computer-controlled mastication simulator]. Schweiz. Monatsschr. Zahnmed. 100, 953-960.

Loomans, B., Opdam, N., Attin, T., Bartlett, D., Edelhoff, D., Frankenberger, R., Benic, G., Ramseyer, S., Wetselaar, P., Sterenborg, B., Hickel, R., Pallesen, U., Mehta, S., Banerji, S., Lussi, A., Wilson, N., 2017. Severe Tooth Wear: European Consensus Statement on Management Guidelines. J. Adhes. Dent. 19, 111-119.

Miyazaki, T., Nakamura, T., Matsumura, H., Ban, S., Kobayashi, T., 2013. Current status of zirconia restoration. J Prosthodont Res 57, 236-261. 
Muts, E.J., van Pelt, H., Edelhoff, D., Krejci, I., Cune, M., 2014. Tooth wear: a systematic review of treatment options. J. Prosthet. Dent. 112, 752-759.

Ozcan, M., Alander, P., Vallittu, P.K., Huysmans, M.C., Kalk, W., 2005. Effect of three surface conditioning methods to improve bond strength of particulate filler resin composites. J Mater Sci Mater Med 16, 21-27.

Ozcan, M., Barbosa, S.H., Melo, R.M., Galhano, G.A., Bottino, M.A., 2007. Effect of surface conditioning methods on the microtensile bond strength of resin composite to composite after aging conditions. Dent. Mater. 23, 1276-1282.

Ozcan, M., Mese, A., 2012. Adhesion of conventional and simplified resin-based luting cements to superficial and deep dentin. Clin. Oral Investig. 16, 1081-1088.

Ozcan, M., Niedermeier, W., 2002. Clinical study on the reasons for and location of failures of metalceramic restorations and survival of repairs. Int. J. Prosthodont. 15, 299-302.

Pjetursson, B.E., Sailer, I., Zwahlen, M., Hammerle, C.H., 2007. A systematic review of the survival and complication rates of all-ceramic and metal-ceramic reconstructions after an observation period of at least 3 years. Part I: Single crowns. Clin. Oral Implants Res. 18 Suppl 3, 73-85.

Porto, T.S., Roperto, R.C., Akkus, A., Akkus, O., Teich, S., Faddoul, F.F., Porto-Neto, S.T., Campos, E.A., 2018. Effect of thermal cycling on fracture toughness of CAD/CAM materials. Am. J. Dent. 31, 205-210.

Raigrodski, A.J., Hillstead, M.B., Meng, G.K., Chung, K.H., 2012. Survival and complications of zirconia-based fixed dental prostheses: a systematic review. J. Prosthet. Dent. 107, 170-177.

Sailer, I., Pjetursson, B.E., Zwahlen, M., Hammerle, C.H., 2007. A systematic review of the survival and complication rates of all-ceramic and metal-ceramic reconstructions after an observation period of at least 3 years. Part II: Fixed dental prostheses. Clin. Oral Implants Res. 18 Suppl 3, 86-96.

Sasse, M., Krummel, A., Klosa, K., Kern, M., 2015. Influence of restoration thickness and dental bonding surface on the fracture resistance of full-coverage occlusal veneers made from lithium disilicate ceramic. Dent. Mater. 31, 907-915.

Schlueter, N., Luka, B., 2018. Erosive tooth wear - a review on global prevalence and on its prevalence in risk groups. Br. Dent. J. 224, 364-370.

Sieper, K., Wille, S., Kern, M., 2017. Fracture strength of lithium disilicate crowns compared to polymer-infiltrated ceramic-network and zirconia reinforced lithium silicate crowns. Journal of the mechanical behavior of biomedical materials 74, 342-348. 
Skouridou, N., Pollington, S., Rosentritt, M., Tsitrou, E., 2013. Fracture strength of minimally prepared all-ceramic CEREC crowns after simulating 5 years of service. Dent. Mater. 29, e70-77.

Steiner, M., Menghini, G., Marthaler, T.M., Imfeld, T., 2010. Changes in dental caries in Zurich school-children over a period of 45 years. Schweiz. Monatsschr. Zahnmed. 120, 1084-1104.

Steiner, M., Mitsias, M.E., Ludwig, K., Kern, M., 2009. In vitro evaluation of a mechanical testing chewing simulator. Dent. Mater. 25, 494-499.

Swain, M.V., Coldea, A., Bilkhair, A., Guess, P.C., 2016. Interpenetrating network ceramic-resin composite dental restorative materials. Dent. Mater. 32, 34-42.

Valderhaug, J., Jokstad, A., Ambjornsen, E., Norheim, P.W., 1997. Assessment of the periapical and clinical status of crowned teeth over 25 years. J. Dent. 25, 97-105.

Varma, S., Preiskel, A., Bartlett, D., 2018. The management of tooth wear with crowns and indirect restorations. Br. Dent. J. 224, 343-347.

Wagner, W.C., Chu, T.M., 1996. Biaxial flexural strength and indentation fracture toughness of three new dental core ceramics. J. Prosthet. Dent. 76, 140-144.

Zhang, Y., Kim, J.W., Bhowmick, S., Thompson, V.P., Rekow, E.D., 2009. Competition of fracture mechanisms in monolithic dental ceramics: flat model systems. Journal of biomedical materials research. Part B, Applied biomaterials 88, 402-411. 